\title{
Design of intelligent diagnosis system for teaching quality based on wireless sensor network and data mining
}

\author{
Yanping Zhang ${ }^{{ }^{*}}$ and Wanwei Huang ${ }^{2}$
}

*Correspondence:
zhangyp@zzuli.edu.cn
${ }^{1}$ Teaching Quality Control
Center, Zhengzhou
University of Light Industry,
Zhengzhou 450002, China
Full list of author information
is available at the end of the
article

\begin{abstract}
With the popularization of computers and various mobile intelligent terminals, intelligent teaching systems based on learners are becoming more and more popular among learners. The above phenomenon has greatly affected and changed the current teaching quality diagnosis methods and models. However, the author found through investigation that the current intelligent teaching quality diagnosis still has different degrees of deficiencies in the design and implementation. In response to the above problems, this paper proposes a teaching quality intelligent diagnosis model based on the combination of wireless sensor networks and fuzzy comprehensive evaluation algorithms. First of all, this article is based on the wireless sensor network to link various levels of intelligent teaching systems, and constructs the information transmission structure of the teaching intelligent diagnosis system. Secondly, this article uses fuzzy comprehensive evaluation and convolutional neural network algorithms to evaluate and excavate intelligent teaching information. Finally, the model successfully passed the simulation test and simulation application, which can provide intelligent diagnosis of teaching quality for modern intelligent teaching system.
\end{abstract}

Keywords: Teaching quality diagnosis, Wireless sensor network, Convolutional neural network, Fuzzy comprehensive evaluation

\section{Introduction}

The development of global information technology provides new means for education. The birth and development of the Internet has provided a broader development space for education, combining modern information technology with education, that is, applying artificial intelligence technology in modern education, making learning a continuous and lifelong process $[1,2]$. With the rapid development of information technology, education is facing new challenges and innovations. In recent years, designers of network learning systems have gradually formed several common course structures for different learning needs [3]. These course structures include: classic personal tutoring courses, student-centered personal tutoring courses, customized online tutoring courses, knowledge-first personal tutoring courses, exploratory personal tutoring courses, and generative personal tutoring courses $[4,5]$.

(C) The Author(s) 2021. Open Access This article is licensed under a Creative Commons Attribution 4.0 International License, which permits use, sharing, adaptation, distribution and reproduction in any medium or format, as long as you give appropriate credit to the original author(s) and the source, provide a link to the Creative Commons licence, and indicate if changes were made. The images or other third party material in this article are included in the article's Creative Commons licence, unless indicated otherwise in a credit line to the material. If material is not included in the article's Creative Commons licence and your intended use is not permitted by statutory regulation or exceeds the permitted use, you will need to obtain permission directly from the copyright holder. To view a copy of this licence, visit http:// creativecommons.org/licenses/by/4.0/. 
Teaching evaluation is not only an activity to judge the value of teaching process and teaching results and serve for teaching decision-making, but also the process of studying the teaching of teachers and the learning of students. For example, Peng-Kyat Pek and Kim-Lang Pooh use Bayesian networks to build student models, and perform probabilistic inferences based on the evidence that student's feedback to the system during the learning process, predict the next behavior of students, and choose the most appropriate Teaching content [6]. Dietrich Albert and Cord Hackneyed obtained the structural similarity between hypertext and knowledge space through the analysis of knowledge space theory, and modeled knowledge [7]. Teaching evaluation is mainly divided into three links: evaluation of teachers' teaching work, evaluation of teachers' teaching, and evaluation of students' learning effects. The types of evaluation can be divided into quantitative evaluation and qualitative evaluation $[8,9]$. There are individual differences between learners, and educators cannot directly obtain learners' psychological abilities and personality characteristics.

In various colleges and universities, the construction of networked courses is on the rise, and how to reflect intelligence in the teaching platform is a hot topic in various networked courses $[10,11]$. At present, most of the existing intelligent products are in the experimental and theoretical research stage, and their intelligence is limited, and they have not yet reached the popularization and application [12]. Therefore, designing an intelligent diagnosis model of teaching quality based on wireless sensor network has very important practical significance [1]. Therefore, in response to the above problems, this paper proposes a teaching quality intelligent diagnosis model based on the combination of wireless sensor networks and fuzzy comprehensive evaluation algorithms. The model is based on the wireless sensor network to construct the information transmission structure of the teaching intelligent diagnosis system, and evaluates the intelligent teaching information and information mining through fuzzy comprehensive evaluation and convolutional neural network algorithms. This model can provide intelligent diagnosis of teaching quality for modern intelligent teaching system.

The rest of this article is organized as follows. Section 2 discusses the teaching quality diagnosis architecture based on wireless sensor network. Then, in Sect. 3, the teaching quality diagnosis based on convolutional neural network and fuzzy comprehensive evaluation is described. Section 4 discusses the actual case analysis of teaching quality diagnosis based on wireless sensor network. Section 5 summarizes the future research directions of the thesis.

\section{Methods}

The development of information technology has greatly changed people's lives. In the 1980s, with the emergence and maturity of wireless sensor technology, wireless sensor networks appeared in people's sight, which aroused people's attention and research [13, 14]. Song Cen et al. proposed Zigzag, an end-to-end packet loss distinguishing algorithm, and ZBS, a packet loss distinguishing algorithm composed of Zigzag, Bias, and Spike. Spike, Bias, and Zigzag have different performances in different network environments, while the ZBS algorithm switches between these three algorithms according to different network environments [15]. A typical wireless sensor network system design mode is shown in Fig. 1. 


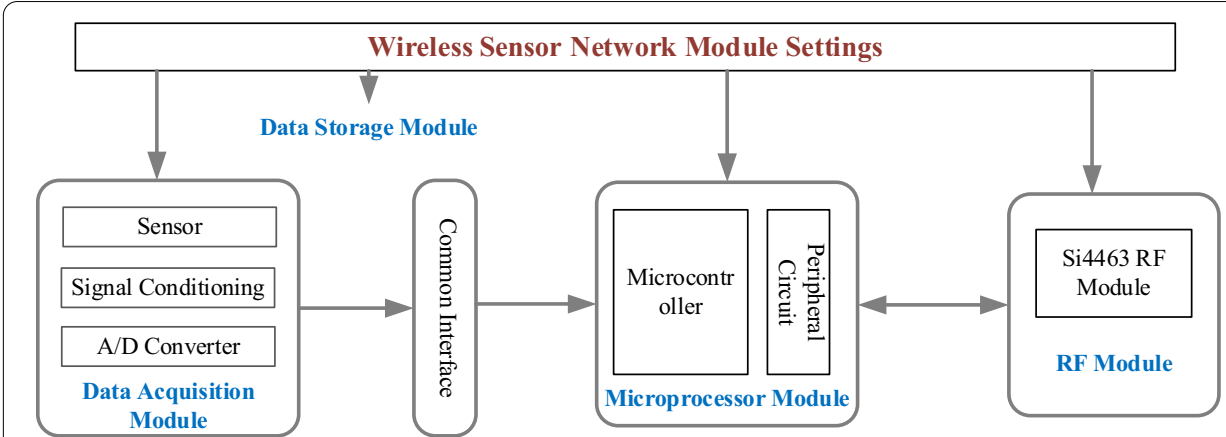

Fig. 1 Design technology of wireless sensor network system

However, the high misclassification rate of ZBS makes ZBS unable to efficiently use wireless bandwidth. The wireless sensor network not only realizes the communication ability between man and nature, but also finds the way of interaction between man and nature, man and computer, computer and nature, so that wireless sensor network can better sense the information of the surrounding environment [16]. At present, the software that can manipulate the sensor nodes in the wireless sensor network generally requires a computer (to send commands), a gateway (to forward information), and sensor nodes (to collect information) to work together to complete the task [17]. Sensor nodes sense and collect information, and other nodes can receive the messages they send. After the information reaches the gateway node, it is forwarded, and finally reaches the management node through the computer.

The observer uses the management node to manage and configure the wireless sensor network; the issuance of monitoring commands and the collection of monitoring data are issued by the observer [18]. Chen et al. proposed the MULTFRC model, which increases the utilization of wireless channels by increasing the number of TFRC streams [19]. According to the performance of TFRC under different conditions, Shen et al. formulated a discrete-time Markov evaluation model on the wireless attenuation channel [20]. This paper proposes an improved adaptive mechanism, which can use packet loss distinguishing parameters to effectively and accurately reflect the state of the network, thereby dynamically and adaptively adjusting the transmission rate according to real-time network conditions, and ultimately ensuring the quality of service of data transmitted by the wireless network. The typical architecture of wireless sensor network is shown in Fig. 2.

In a wireless sensor network, the same area may be monitored by multiple sensor nodes at the same time, and some areas are repeatedly monitored [21]. In this case, the wireless sensor network will generate redundant nodes, causing energy waste and rising costs. In the face of such a situation, we can conduct scheduling research on sensor nodes, so that the nodes change between sleep and wakeup states [22]. In some important application areas, there are very high requirements for the network coverage of wireless sensor networks. Therefore, in order to improve the network coverage and effective transmission range of the teaching quality intelligent diagnosis system designed in this paper, this paper takes node scheduling as an effective means to improve the network coverage capacity for research and design [23]. 


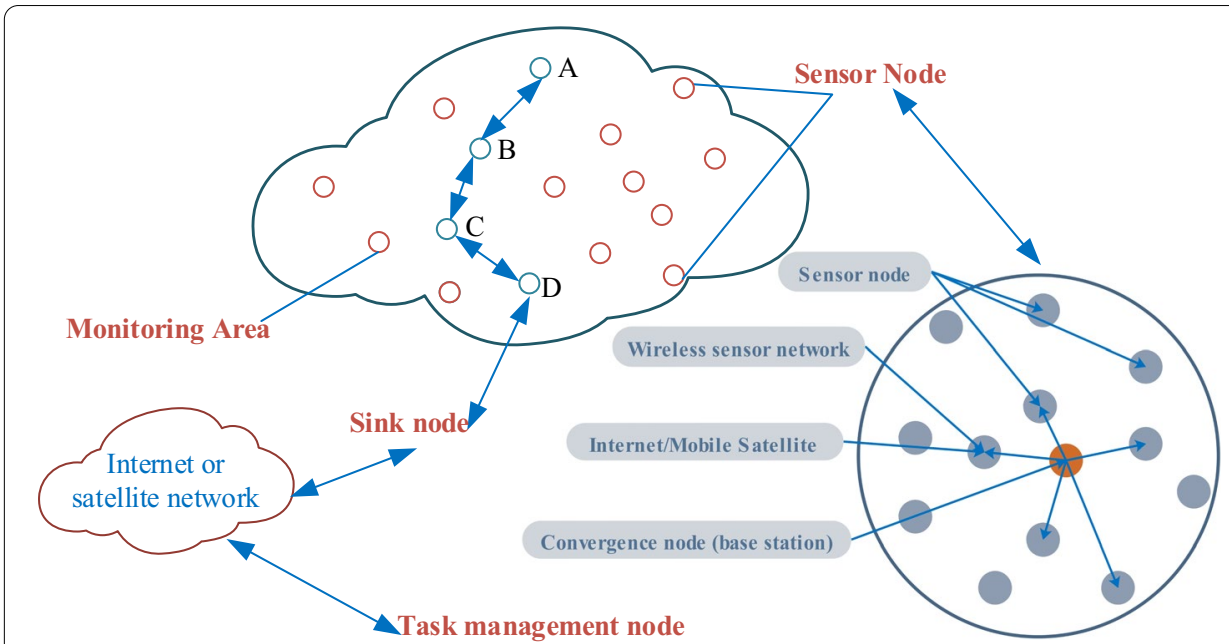

Fig. 2 Typical architecture of wireless sensor network

\section{Teaching quality diagnosis based on convolutional neural network and fuzzy comprehensive evaluation}

The birth and development of the Internet has provided a broader development space for education and organically combined modern information technology with education. That is, the application of artificial intelligence technology in modern education makes learning a continuous and lifelong process. In this case, computer-assisted teaching systems supported by multimedia technology and network technology are developing rapidly. This teaching method aims to combine traditional classroom teaching with modern information technology, and implement the complementary advantages of online courses and traditional classrooms [6]. For students from different starting points, strengthen the cultivation of independent learning ability, pay attention to personality differences, and develop students' potential. This method uses a multimedia environment to implement three-dimensional, diversified and individualized teaching, students can share more teaching resources, and there is great flexibility in learning methods, learning locations and learning time arrangements.

\subsection{Teaching quality evaluation based on fuzzy comprehensive evaluation}

According to the fuzzy comprehensive evaluation structure diagram and the construction of the judgment matrix, this article compares the elements of each layer pairwise to obtain the comparison judgment matrix. The level analysis judgment matrix table of the teaching quality intelligent diagnosis system is shown in Table 1.

In the consistency check of the judgment matrix, when the judgment matrix cannot be guaranteed to have complete consistency, the characteristic roots of the corresponding judgment matrix will also change. Therefore, this paper can use the change of the characteristic root of the judgment matrix to test the consistency of judgment [24]. Therefore, this paper uses the negative average value of the other characteristic roots except the largest characteristic root as the index to measure the deviation of the judgment matrix. 
Table 1 AHP judgment matrix

\begin{tabular}{lllllll}
\hline$A$ & $B_{1}$ & $B_{2}$ & $B_{3}$ & $B_{4}$ & $B_{5}$ & $B_{6}$ \\
\hline$B_{1}$ & 1 & $1 / 3$ & $1 / 3$ & $1 / 3$ & $1 / 4$ & $1 / 5$ \\
$B_{2}$ & 3 & 1 & 2 & $1 / 3$ & $1 / 4$ & $1 / 5$ \\
$B_{3}$ & 3 & $1 / 2$ & 1 & $1 / 3$ & $1 / 4$ & $1 / 5$ \\
$B_{4}$ & 3 & 3 & 3 & 1 & $1 / 3$ & $1 / 4$ \\
$B_{5}$ & 4 & 4 & 4 & 3 & 1 & $1 / 3$ \\
$B_{6}$ & 5 & 5 & 3 & 4 & 3 & 1 \\
\hline
\end{tabular}

Table 2 1-14 judgment matrix table

\begin{tabular}{llllllll}
\hline Matrix index & $\mathbf{1}$ & $\mathbf{2}$ & $\mathbf{3}$ & $\mathbf{4}$ & $\mathbf{5}$ & $\mathbf{6}$ & $\mathbf{7}$ \\
\hline Serial number & 1.542 & 1.21 & 1.42 & 0.01 & 0.12 & 0.45 & 1.43 \\
Matrix index & 8 & 9 & 10 & 11 & 12 & 13 & 14 \\
Serial number & 1.32 & 1.12 & 1.33 & 1.23 & 1.49 & 1.32 & 1.12 \\
\hline
\end{tabular}

$$
\mathrm{CI}=\frac{\lambda_{\max }-n}{n-1}
$$

In order to measure whether the judgment matrices of different levels are consistent, this paper introduces the average random consistency index value of the judgment matrix (Table 2).

That is to say, the judgment matrix is considered to have satisfactory consistency, otherwise it is necessary to adjust the judgment matrix to make it have satisfactory consistency.

Calculate the product of each row element of the judgment matrix.

$$
M_{i}=\prod_{j=1}^{n} a_{i j}, i=1,2, \ldots, n
$$

Compute the nth root of $M_{i}$.

$$
\bar{W}_{i}=\sqrt[n]{M_{i}}
$$

Normalize the vector $\bar{W}=\left[\bar{W}_{1}, \bar{W}_{2}, \ldots, \bar{W}_{n}\right]^{\mathrm{T}}$.

$$
W_{i}=\frac{\bar{W}_{i}}{\sum_{j=1}^{n} \bar{W}_{j}}
$$

Then, $W=\left[W_{1}, W_{2}, \ldots, W_{n}\right]^{\mathrm{T}}$ is the required feature vector.

\subsection{Data mining of teaching quality based on convolutional neural network}

By applying the convolutional neural network algorithm to the design of the teaching cognitive diagnosis model, on the one hand, it can solve the problem that the computer cannot recognize the mental activity of the person in the network learning system, and judge the knowledge state of the learner in time. On the other hand, it provides 
a possibility for learners to follow-up learning in a targeted manner [25]. This paper mainly studies the teaching quality diagnosis model based on convolutional neural network algorithm. Aiming at the problem that the current network learning support system cannot really realize personalized learning, it is proposed to apply the measurement theory of convolutional neural network algorithm to the design of the network learning support system. This model pays more attention to the knowledge level of the subjects, making online learning more intelligent and humane.

The convolutional neural network model is a deep feedforward neural network constructed by multi-layer convolutional operation layers and related functional modules. It is one of the main development directions of deep learning technology [26]. This technology has been widely used in computer vision, natural language processing and other fields in recent years. The schematic diagram of convolution operation and transposed convolution operation is shown in Fig. 3. Since the data collection is discrete in space, the amplitude is also discrete after A/D transformable, so discrete convolution should be performed. From the above, it corresponds to taking the variable $n$. Corresponding to take the variable as $\mathrm{m}$, so there are:

$$
\tilde{p}(n, m)=p(n, m) * h(n)=\sum_{L=-N_{1}}^{N_{1}} p(n-l, m) h(l)
$$

Considering that the formula (5) is fixed and can be ignored temporarily, and because it is symmetric, the formula (6) can be transformed into:

$$
\left.\begin{array}{l}
\tilde{p}(0)=h(-255) p(-255)+\cdots+h(0) p(0)+\cdots+h(255) p(255) \\
\tilde{p}(0)=h(-255) p(-255)+\cdots+h(0) p(0)+\cdots+h(255) p(255) \\
\vdots \\
\tilde{p}(0)=h(-255) p(-255)+\cdots+h(0) p(255)+\cdots+h(255) p(255)
\end{array}\right\}
$$

The convolutional neural network algorithm is used here, and the forward conduction operation is first performed through the neural network. Through the above method, the activation values of all neural nodes in each network layer in the neural network are obtained, and the output value of the neural network loss function is calculated at the same time.

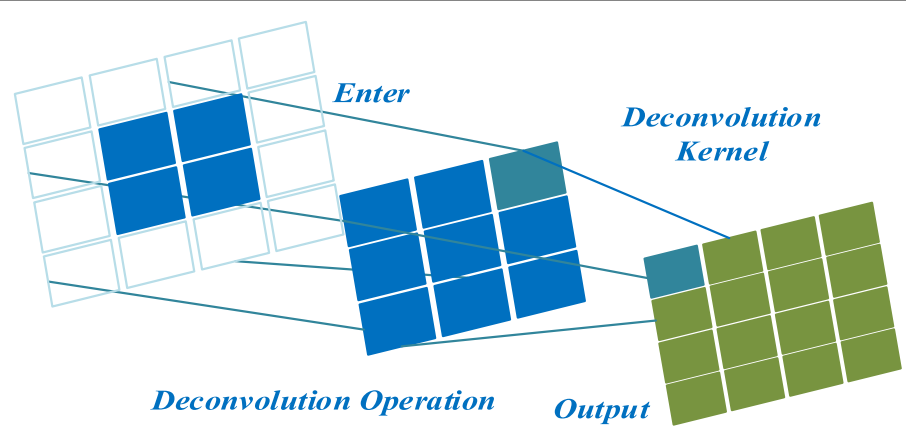

Fig. 3 Schematic diagram of convolution operation and transposed convolution operation 
Then, for each neural node $\mathrm{i}$ in the first neural network layer, get its residual. The residual indicates the degree of influence of the neural node on the residual of the final output value of the neural network. The difference between the final output value of the neural network and the actual sample label value. For the residual of the neural node in the hidden layer of the neural network, the residual of the neural node is calculated by the weighted average of the residuals of all the neural nodes. According to the convolutional neural network node residual algorithm, the node residual of each neural node in the neural network layer can be obtained [27].

$$
\delta_{i}^{\left(n_{1}\right)}=\frac{\partial}{\partial z_{i}^{\left(n_{1}\right)}} J(W, b ; x, y)
$$

For the neural network layer of the second layer, the calculation formula of the node residual of the neural node of the neural network layer is as (8).

$$
\delta_{i}^{\left(n_{1}\right)}=\frac{\partial}{\partial z_{i}^{\left(n_{1}\right)}} \frac{1}{2}\left\|y-h_{w, b}(x)\right\|^{2}=-\left(y_{i}-a_{i}^{\left(n_{1}\right)}\right) \cdot f^{\prime}\left(z_{i}^{\left(n_{1}\right)}\right)
$$

Simply replace the relationship with (9):

$$
\begin{aligned}
\delta_{i}^{\left(n_{1}\right)} & =\frac{\partial}{\partial z_{i}^{\left(n_{1}\right)}} J(W, b, x, y)=\frac{\partial}{\partial z_{i}^{\left(n_{1}\right)}} \frac{1}{2}\left\|y-h_{w, p}(x)\right\|^{2} \\
& =\left(\sum_{j=1}^{S_{s q}} W_{j i}^{n_{1}-1} \delta_{j}^{\left(n_{1}\right)}\right) f^{\prime}\left(z_{i}^{\left(n_{1}-1\right)}\right)
\end{aligned}
$$

The above formula represents the weighted sum of unit inputs. Backpropagation is based on the chain rule to derivate from back to front, and finally find the residual value of all neural network nodes [28-31].

$$
\delta_{i}^{(l)}=\left(\sum_{j=1}^{S_{l+1}} W_{j i}^{(l)} \delta_{j}^{(l+1)}\right) f^{\prime}\left(z_{i}^{(l)}\right)
$$

With the formula for calculating the residuals of each node of the neural network, the weight parameters and partial derivatives of the neural network loss function can be calculated separately. The relationship between the partial derivative of the loss function with respect to the parameter and the node is as in Eq. (10).

\section{Experiment}

\subsection{Selection of teaching quality diagnosis cases}

After selecting the model method and architecture, this article will conduct performance testing of related models. In recent years, designers of network learning systems have gradually formed several common course structures for different learning needs. These course structures include: classic personal tutoring courses, student-centered personal tutoring courses, customized online tutoring courses, knowledge-first personal tutoring courses, exploratory personal tutoring courses and generative personal tutoring courses $[32,33]$. In response to the above problems, this paper proposes a teaching quality 
intelligent diagnosis model based on the combination of wireless sensor networks and fuzzy comprehensive evaluation algorithms. On this basis, we will select teaching quality diagnosis cases for performance testing according to relevant standards.

\subsection{Teaching quality diagnostic performance test}

In the above research, this paper constructs an intelligent diagnosis model of teaching quality based on wireless sensor network [34,35]. After selecting test cases according to relevant standards, we conducted model performance testing and comparative analysis. In this test, we mainly selected the throughput performance of wireless sensor network under TCP/TFRC agent and the correct rate of network diagnosis of teaching quality diagnosis under different environments and methods as the test indicators. Based on the same network configuration and environment, different delay jitter change trend graphs are obtained. Figure 4 shows the delay jitter change graphs of TFRC and TFRC streams [36]. The average delay jitter of the TFRC stream is $0.006 \mathrm{~s}$, while the average delay jitter of the TFRC stream is reduced to $0.003 \mathrm{~s}$, which reflects that the Adaptive-TFRC algorithm has better real-time performance and transmission stability, and is more effective in packet loss control. It is also more suitable for wireless network streaming media transmission. Figure 4 shows the comparison of throughput performance of wireless sensor networks under TCP/TFRC proxy.

From Fig. 4, we can see that when the target test environment is selected as the TCP/ TFRC mode, the teaching quality intelligent diagnosis model established in this paper only needs 6 sensor nodes to cover the target area completely. At the same time, traditional models and algorithms require more than 10 sensor nodes to work to fully cover the target area. When $a=60$, this algorithm only needs 6 working nodes, while the traditional algorithm needs 10 working nodes. Therefore, it can be seen that when the same target area is completely covered, the number of nodes required by this algorithm is less than the number of nodes required by the traditional algorithm, which reflects the advantages of this algorithm. In addition, the minimum number of nodes is used to achieve $100 \%$ probability of covering the target area. If the observer only needs to observe a part of the target area, the algorithm in this paper is also applicable. The

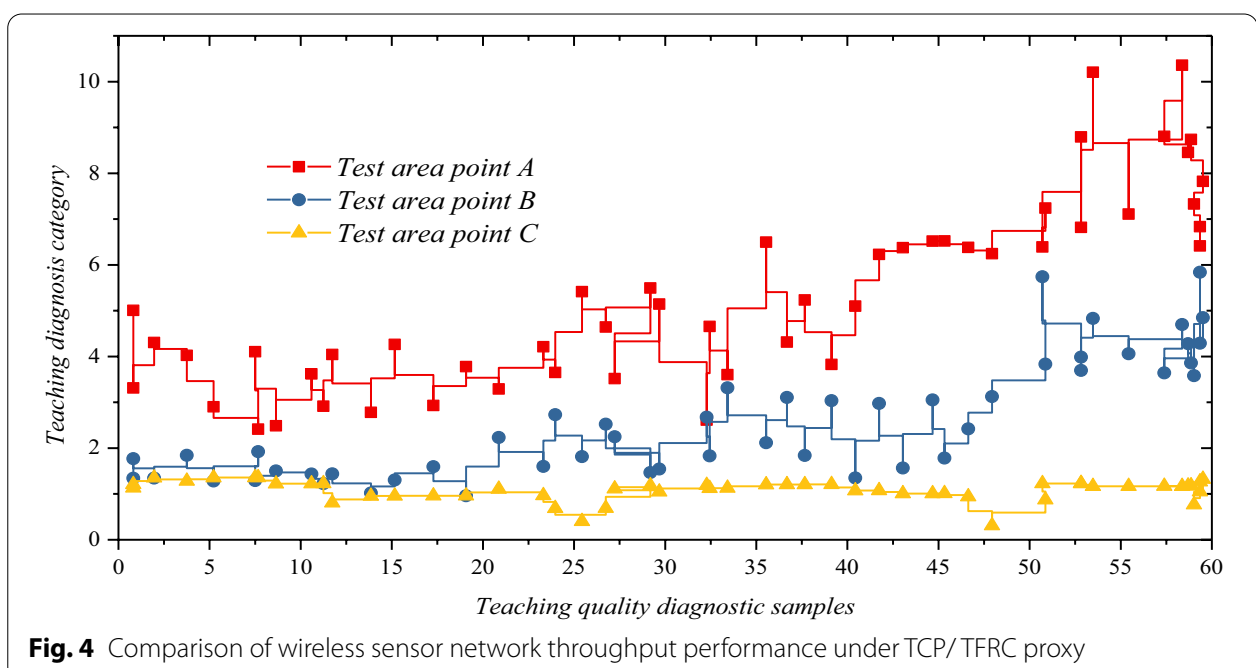




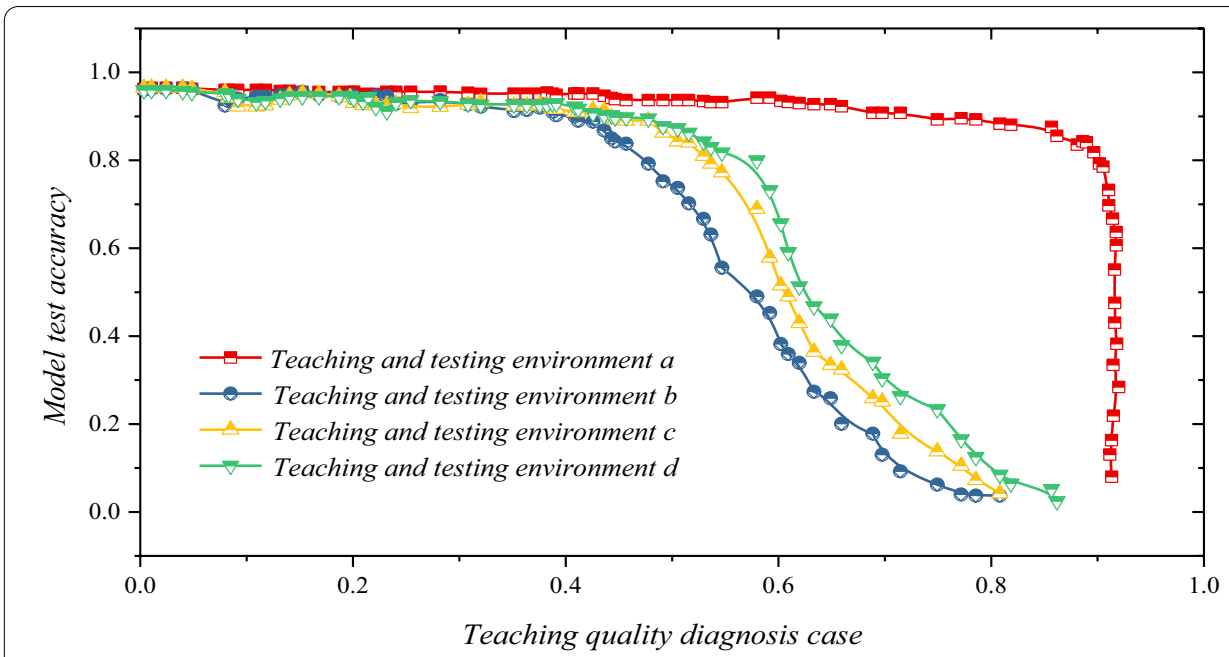

Fig. 5 Teaching quality diagnosis network diagnosis test in different environments

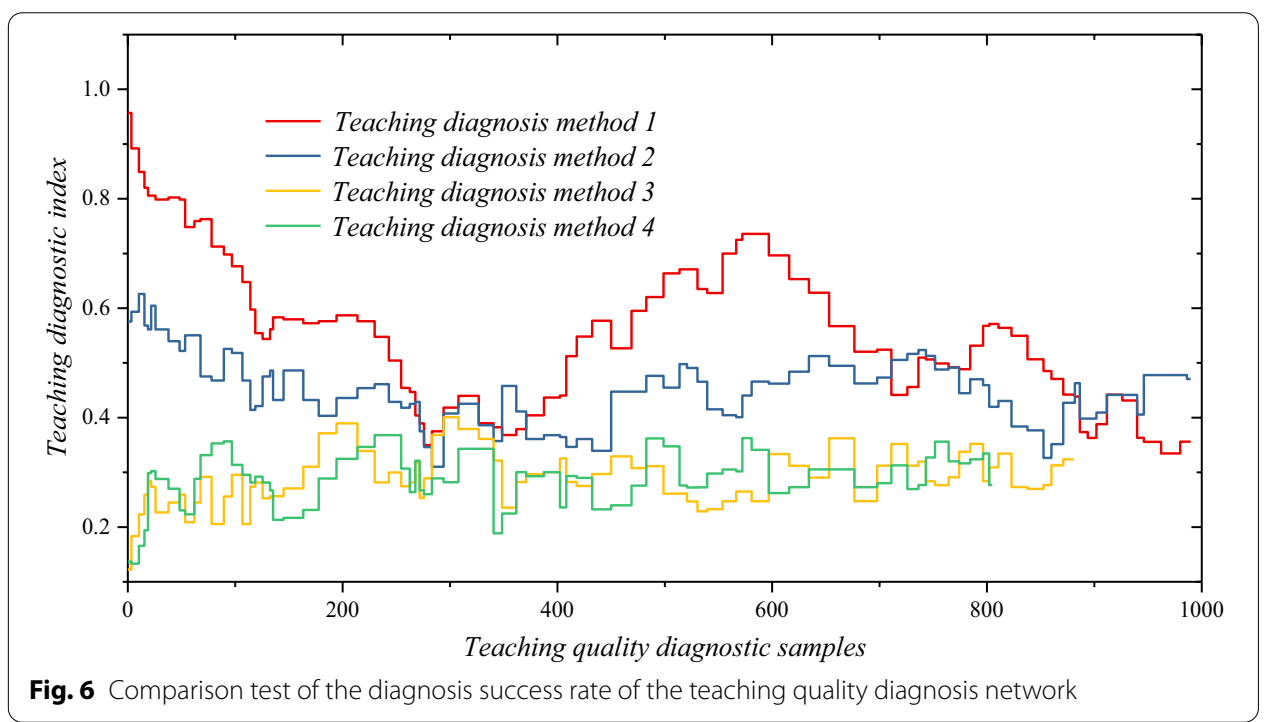

algorithm obtained in this paper usually performs better, the calculation speed is greatly improved, the number of nodes required for real-time calculation, the shortcomings of high energy consumption of network nodes are improved, and the application cost is reduced. Figure 5 shows the network diagnosis test of teaching quality diagnosis in different environments.

The teaching quality diagnosis model established in this article is tested in different environments. From the experimental results in Fig. 5, the model has achieved good experimental results in different experimental environments. With the gradual increase in test samples, the error rate of network diagnosis of teaching quality diagnosis gradually decreased, and more consistent results were obtained. After conducting network diagnosis tests for teaching quality diagnosis in different environments, we compared the model established in this article with the methods mentioned in other documents, and the results are shown in Fig. 6. 
Here, the teaching quality diagnosis model and different methods established in this article are tested. From the experimental results in Fig. 6, the model has achieved good experimental results when compared with different methods. With the gradual increase in test samples, the error rate of network diagnosis of teaching quality diagnosis gradually decreased, and more consistent results were obtained. According to the results, compared with several other algorithms, the performance of the convolutional neural network algorithm is very good. Therefore, the experimental results prove that the retrieval accuracy of convolutional neural networks is significantly better than the information mining capabilities of other methods, and can provide more accurate information mining and extraction for the teaching quality diagnosis process. After the above analysis and testing process, the verification result shows the high efficiency and applicability of the model established in this paper. However, through the work of this paper, some new ideas can be provided for the follow-up research of this topic, which will be helpful to the subsequent research work.

\section{Results and discussion}

The application of artificial intelligence technology in modern education makes learning a continuous and lifelong process. With the rapid development of information technology, education is facing new challenges and innovations. In recent years, designers of network learning systems have gradually formed several common course structures for different learning needs. However, the existing courses have the problems of low degree of information and insufficient transparency of teaching quality diagnosis, which has led to the further development of relevant courses.

In response to the above problems, this paper proposes a teaching quality intelligent diagnosis model based on the combination of wireless sensor networks and fuzzy comprehensive evaluation algorithms. First of all, this article is based on the wireless sensor network to link various levels of intelligent teaching systems, and constructs the information transmission structure of the teaching intelligent diagnosis system. Secondly, this article uses fuzzy comprehensive evaluation and convolutional neural network algorithms to evaluate and excavate intelligent teaching information. Finally, the model successfully passed the simulation test and simulation application, which can provide intelligent diagnosis of teaching quality for modern intelligent teaching system. Although this article has made some research results in the existing teaching quality intelligent diagnosis model, there are still many problems that need to be improved. In the future, we will carry out further research in this area, with a view to contributing to the process of modern education intelligence.

\section{Abbreviations}

WSN: Wireless sensor network.

Acknowledgements

None

Authors' contributions

YZ and WH have a common level of contribution to the manuscript. All authors read and approved the final manuscript.

Funding

None. 
Availability of data and materials

The datasets used and/or analyzed during the current study are available from the corresponding author on reasonable request.

Ethical approval and consent to participate

This article does not contain any studies with human participants or animals performed by any of the authors.

\section{Consent for publication}

All authors agree to submit this version and claim that no part of this manuscript has been published or submitted elsewhere.

Competing interests

Declares that he has no conflict of interest.

\section{Author details}

${ }^{1}$ Teaching Quality Control Center, Zhengzhou University of Light Industry, Zhengzhou 450002, China. ${ }^{2}$ College of Software Engineering, Zhengzhou University of Light Industry, Zhengzhou 450002, China.

Received: 22 October 2020 Accepted: 12 January 2021

Published online: 21 January 2021

\section{References}

1. Z. Zheng, N.P. Molotch, C.A. Oroza, M.H. Conklin, R.C. Bales, Spatial snow water equivalent estimation for mountainous areas using wireless-sensor networks and remote-sensing products. Remote Sens. Environ. 215, 44-56 (2018)

2. Y. Zhang, Y. Zhu, F. Yan, W. Xia, L. Shen, Energy-efficient radio resource allocation in software-defined wireless sensor networks. IET Commun. 12(3), 349-358 (2018)

3. X. Wang, J. Du, R. Zou, Z. Zhou, Key node identification of wireless sensor networks based on cascade failure. Mod. Phys. Lett. B 1, 2050394 (2020)

4. P. Nematollahi, M. Naghibzadeh, S. Abrishami, M.H. Yaghmaee, Distributed clustering-task scheduling for wireless sensor networks using dynamic hyper round policy. IEEE Trans. Mob. Comput. 17(99), 334-347 (2018)

5. M. Leinonen, M. Codreanu, M. Juntti, Distributed distortion-rate optimized compressed sensing in wireless sensor networks. IEEE Trans. Commun. 66, 1 (2018)

6. J. Kulshrestha, M.K. Mishra, Energy balanced data gathering approaches in wireless sensor networks using mixedhop communication. Computing 100(10), 1-26 (2018)

7. J. Gong, T.H. Chang, C. Shen, X. Chen, Flight time minimization of UAV for data collection over wireless sensor networks. IEEE J. Sel. Areas Commun. 36, 1942-1954 (2018)

8. A.E. Ghazi, B.D. Ahiod, Energy efficient teaching-learning-based optimization for the discrete routing problem in wireless sensor networks. Appl. Intell. 48, 2755-2769 (2018)

9. X. Fu, H. Yao, Y. Yang, Exploring the invulnerability of wireless sensor networks against cascading failures. Inf. Sci. 491, 289 (2019)

10. X. Bai, Z. Wang, L. Sheng, Z. Wang, Reliable data fusion of hierarchical wireless sensor networks with asynchronous measurement for greenhouse monitoring. IEEE Trans. Control Syst. Technol. 26(2), 342-356 (2018)

11. S. Althunibat, R. Mesleh, Index modulation for cluster-based wireless sensor networks. IEEE Trans. Veh. Technol. PP(8), $1(2018)$

12. M.A. Al-Jarrah, A. Al-Dweik, M. Kalil, S.S. Ikki, Decision fusion in distributed cooperative wireless sensor networks. IEEE Trans. Veh. Technol. 68, 797-811 (2018)

13. W. Xu, W. Liang, X. Jia, Z. Xu, Z. Li, Y. Liu, Maximizing sensor lifetime with the minimal service cost of a mobile charger in wireless sensor networks. IEEE Trans. Mob. Comput. 17, 1 (2018)

14. G. Verma, V. Sharma, A novel thermoelectric energy harvester for wireless sensor network application. IEEE Trans. Ind. Electron. 66, 3530-3538 (2019)

15. K. Sheehan, B. Sobolev, P. Guy, Fractures, ISQUA16-1366 HIP fracture mortality by teaching status of treating hospital. Int. J. Quality Health Care 28(suppl_1), 17 (2016)

16. A.A. Shah, C.K. Zogg, S.L. Nitzschke, N.R. Changoor, J.M. Havens, A. Salim, Z. Cooper, A.H. Haider, Evaluation of the perceived association between resident turnover and the outcomes of patients who undergo emergency general surgery: questioning the July phenomenon. Jama Surg. 151, 217 (2015)

17. J.A. Perez, M. Awar, A. Nezamabadi, R. Ogunti, M. Puppala, L. Colton, J.M. Clewing, S. Ketkar, S.T.C. Wong, R.J. Robbins, Comparison of direct patient care costs and quality outcomes of the teaching and non-teaching hospitalist services at a large academic medical center. Acad. Med. 93, 491-497 (2017)

18. I.A. Mjör, V.V. Gordan, Failure, repair, refurbishing and longevity of restorations. Oper. Dent. 27(5), 528-534 (2016)

19. E. Mesquita, A. Arêde, N. Pinto, P. Antunes, H. Varum, Long-term monitoring of a damaged historic structure using a wireless sensor network. Eng Struct 161, 108-117 (2018)

20. D.M.D. Manfred, N.-D.P.D. Trong-Nghia, H.P.D. Peter, The UICC telepathology consultation center. Cancer 89(1), 187-191 (2015)

21. T. Lu, G. Liu, S. Chang, Energy-efficient data sensing and routing in unreliable energy-harvesting wireless sensor network. Wirel. Netw. 24, 611-625 (2018)

22. C.C. Liao, C.K. Ting, A novel integer-coded memetic algorithm for the set k-cover problem in wireless sensor networks. IEEE Trans. Cybern. 48, 1-14 (2018)

23. Y. Li, S. Zhou, Q. Zhu, B. Li, J. Wang, C. Wang, L. Chen, S. Wu, Automated moving object classification in wireless multimedia sensor networks. Environ. Pollut. 17, 1116-1131 (2018) 
24. D.M. Kobewka, C. Van Walraven, J. Turnbull, J. Worthington, L. Calder, A. Forster, Quality gaps identified through mortality review. BMJ Qual. Saf. 26(2), 141-149 (2017)

25. C. Knowles, D. Treanor, Maintaining quality diagnosis with digital pathology: a practical guide to ISO 15189 accreditation. J. Clin. Pathol. 72, 663-668 (2019)

26. M. Hua, Y. Wang, Z. Zhang, C. Li, Y. Huang, L. Yang, Power-efficient communication in UAV-aided wireless sensor networks. IEEE Commun. Lett. 22, 1264-1267 (2018)

27. B.S. Hsu, B.D. Meyer, S.A. Lakhani, Financial, resource utilization, and mortality impacts of teaching hospital status on pediatric patients admitted for sepsis. Pediatr. Infect. Dis. J. 36(8), 1 (2017)

28. C.M. Holloway, L. Alriyees, R. Saskin, Utilization of percutaneous needle biopsy for breast diagnosis in a comprehensive breast center: implications for development of quality indicators. World J. Surg. 40(7), 1-10 (2015)

29. H. Liang, J. Zou, K. Zuo, M.J. Khan, An improved genetic algorithm optimization fuzzy controller applied to the wellhead back pressure control system. Mech. Syst. Signal Process. 142, 106708 (2020)

30. W. Guo, N. Xiong, H.C. Chao, S. Hussain, G. Chen, Design and analysis of self-adapted task scheduling strategies in wireless sensor networks. Sensors 11(7), 6533-6554 (2011)

31. H. Zheng, W. Guo, N. Xiong, A kernel-based compressive sensing approach for mobile data gathering in wireless sensor network systems. IEEE Trans. Syst. Man Cybern. Syst. 48(12), 2315-2327 (2017)

32. H. Liang, D. Zou, Z. Li, K. Muhammad Junaid, Y. Lu, Dynamic evaluation of drilling leakage risk based on fuzzy theory and PSO-SVR algorithm. Future Gener. Comput. Syst. 95, 454-466 (2019)

33. R. He, N. Xiong, L.T. Yang, J.H. Park, Using multi-modal semantic association rules to fuse keywords and visual features automatically for web image retrieval. Inf. Fusion 12(3), 223-230 (2011)

34. W. Wei, B. Zhou, D. Polap, M. Wozniak, A regional adaptive variational PDE model for computed tomography image reconstruction. Pattern Recognit. 92, 64-81 (2019)

35. Y. Sun, C. Xu, G. Li, W. Xu, J. Kong, D. Jiang, B. Tao, D. Chen, Intelligent human computer interaction based on non redundant EMG signal. Alex. Eng. J. 59(3), 1149-1157 (2020)

36. H. Liang, A. Xian, M. Min Mao, P. Ni, H. Wu, A research on remote fracturing monitoring and decision-making method supporting smart city. Sustain. Cities Soc. 62, 102414 (2020)

\section{Publisher's Note}

Springer Nature remains neutral with regard to jurisdictional claims in published maps and institutional affiliations.

\section{Submit your manuscript to a SpringerOpen ${ }^{\odot}$ journal and benefit from:}

- Convenient online submission

- Rigorous peer review

- Open access: articles freely available online

- High visibility within the field

Retaining the copyright to your article

Submit your next manuscript at $\mathbf{s p r i n g e r o p e n . c o m ~}$ 